\title{
Ovarian teratomas: clinicopathological study at tertiary care center
}

\author{
Sunil Vitthalrao Jagtap ${ }^{1 *}$, Nitin S. Kshirsagar², Shubham S. Jagtap ${ }^{3}$, Saswati Boral ${ }^{1}$, \\ Nitesh Nasre ${ }^{1}$
}

\author{
${ }^{1}$ Department of Pathology, Krishna Institute of Medical Sciences Deemed University, Maharashtra, India \\ ${ }^{2}$ Department of Obstetrics and Gynecology, Krishna Institute of Medical Sciences Deemed University, Maharashtra, \\ India \\ ${ }^{3}$ Medical UG, VMMC, GMC, Solapur, Maharashtra, India
}

Received: 06 May 2019

Accepted: 11 June 2019

\section{*Correspondence:}

Dr. Sunil Vitthalrao Jagtap,

E-mail: drsvjagtap@gmail.com

Copyright: (c) the author(s), publisher and licensee Medip Academy. This is an open-access article distributed under the terms of the Creative Commons Attribution Non-Commercial License, which permits unrestricted non-commercial use, distribution, and reproduction in any medium, provided the original work is properly cited.

\section{ABSTRACT}

Background: Teratomas are belonging to a group of germ cell tumors. It is also referred to as dermoid cyst. Teratomas are most common germ cell tumor of the ovary. Teratomas are composed of various histological types. In this article we are presenting various morphological patterns, its clinical manifestation and its clinical significance.

Methods: This is prospective study for a period of 3 years from March 2016 to February 2019 at tertiary care hospital. It consists of total evaluation of 82 cases of ovarian lesions which were surgically excised for clinically or radiologically suspected of ovarian neoplasm.

Results: A total of 82 cases of ovarian specimen were included out of which 18 cases were of ovarian teratoma. In these 17 cases were benign teratomas, 1 case of immature teratoma. All the cases of mature teratoma were predominantly of cystic type with focal solid areas. Right sided ovary was involved in $44.5 \%$ cases while left sided in $55.5 \%$ cases. The tumor size ranges from $2.5 \mathrm{~cm}$ to $20.8 \mathrm{cms}$. The age range in this study was from 20 to 60 year. The common age observed for ovarian teratoma was in group of 31-40 years, having 6 cases. The clinically most of cases were asymptomatic or presented with unexplained abdominal pain or palpable mass. USG finding in most of cases were diffuse or partial echogenic mass lesion with cystic nature and echogenic bands.

Conclusions: In our study showed mature cystic teratoma is the most common type of ovarian teratomas. The immature and monodermal types are rare. The histopathological examination plays important role in final diagnosis and patient management.

Keywords: Gonad, Ovarian neoplasm, Ovarian cyst, Teratoma

\section{INTRODUCTION}

Teratomas are complex tumors composed of tissue derived from 3 different types of germ cell layers ectoderm, mesoderm and endoderm. ${ }^{1}$ It has been studied that mature cystic teratomas arise from a single germ cell after the first meiotic division. ${ }^{2}$ A mature teratoma is a grade 0 teratoma. Mature teratomas are highly variable in form and histology, and may be solid, cystic, or a combination of solid and cystic. The tumors are unilocular in $88 \%$ of cases and are filled with sebaceous material. ${ }^{3}$ Cysts are lined by squamous or transitional epithelium with sometime abundant hairs or desquamated material. A teratoma often contains several types of tissue. It typically contains mature tissues of ectodermal like skin, brain, mesodermal like cartilage, muscle, fat and endodermal like mucinous or ciliated epithelium of intestinal type, mucus gland origin. Teratomas are most 
frequent germ cell tumors of ovary. These are divided in to 3 main groups: (a) mature teratoma, (b) immature (malignant) teratoma, (c) monodermal teratoma - which include struma ovarii, carcinoid tumor, neural tumors or combination as struma-carcinoid. It contains cells from only one type of tissue. ${ }^{4}$

\section{METHODS}

This was prospective study for a period of 3 years from March 2016 to February 2019 at our rural tertiary care hospital in Maharashtra. For which all surgically excised specimens of ovarian lesions were included like panhysterectomy, uni or bilateral oopherecctomy, ovarian mass lesions etc. (Figure 1, 2 and 3). A choice of an operative procedure is either laparoscopic or open surgical removal. We received total 82 cases of ovarian lesions.

\section{Inclusion criteria}

Microscopically diagnosed cases of teratomas were taken for this study.

\section{Exclusion criteria}

Ovarian neoplasms other than ovarian teratoma cases were excluded. The detailed demographic data, clinical presenting symptoms and signs of patients, relevant radio immaging findings biochemical, and tumor marker etc. investigations were considered. The details of surgical procedures and on histopathology gross and microscopic features were studied. Representative sections from ovarian tumors were taken and tissue sections were stained by haematoxylin and eosin stain. Final histopathological diagnosis was made and types of teratomas were categorised (Figures 4, 5, 6 and 7). The extents of tumor, associated changes etc were noted.

\section{Statistical analysis}

Data were entered and analyzed using the statistical package for the social science (SPSS). Nominal data were expressed as frequency and percentage. The data was analyzed and interpretation is done. The study was approved by Institutional Ethic Committee.

\section{RESULTS}

All surgically excised specimens of ovarian lesions were included like panhysterectomy, uni or bilateral oopherecctomy, ovarian mass lesions etc. In Figure 1 the panhysterectomy specimen showing uterus, cervix along with ovarian mass. The cut open ovarian mass showing cystic lesion with sebaceous material and hair tuft. This case was diagnosed as mature cystic teratoma. Figure 2 showing ovarian cut open specimen with cystic lesion filled by sebaceous material and hair tuft.

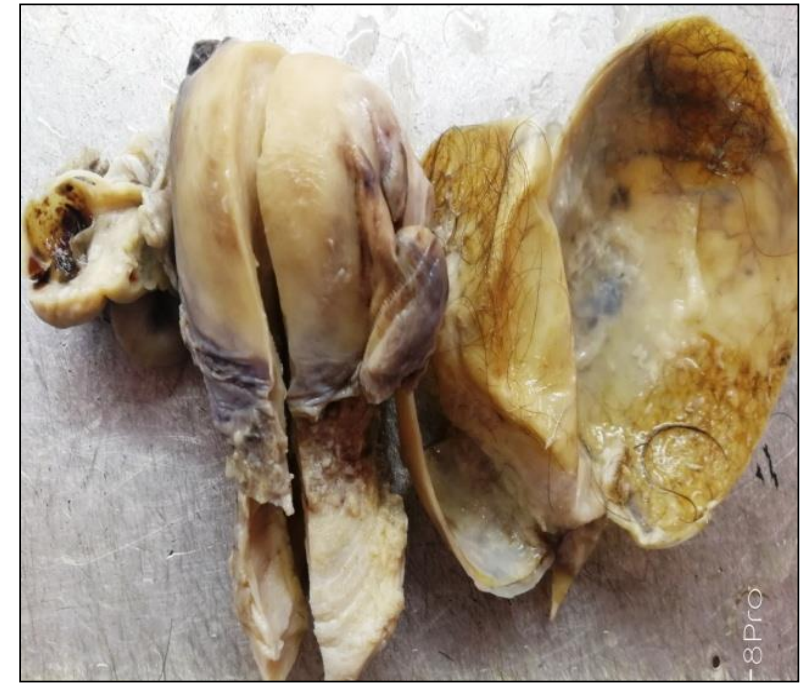

Figure 1: Panhysterectomy specimen of cut open ovarian mature teratoma.

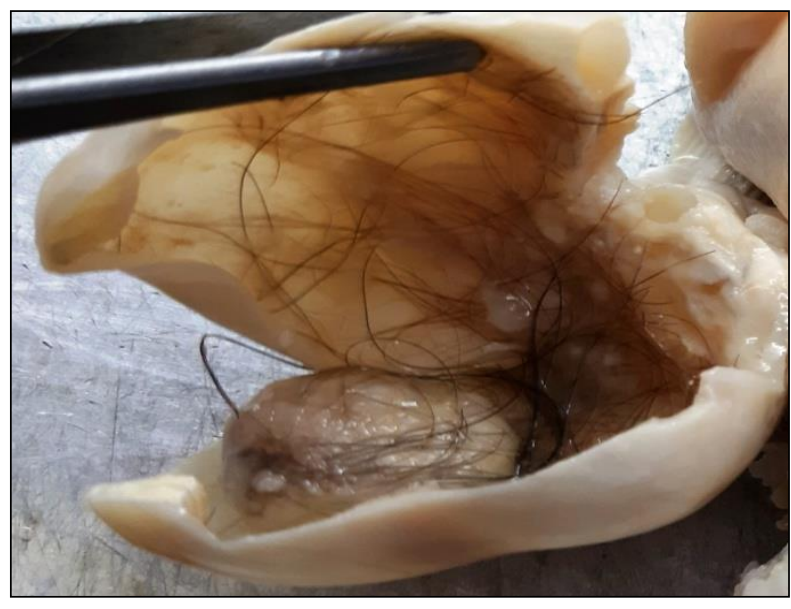

Figure 2: Specimen of cystic ovarian teratoma with sebaceous material and hair tuft.

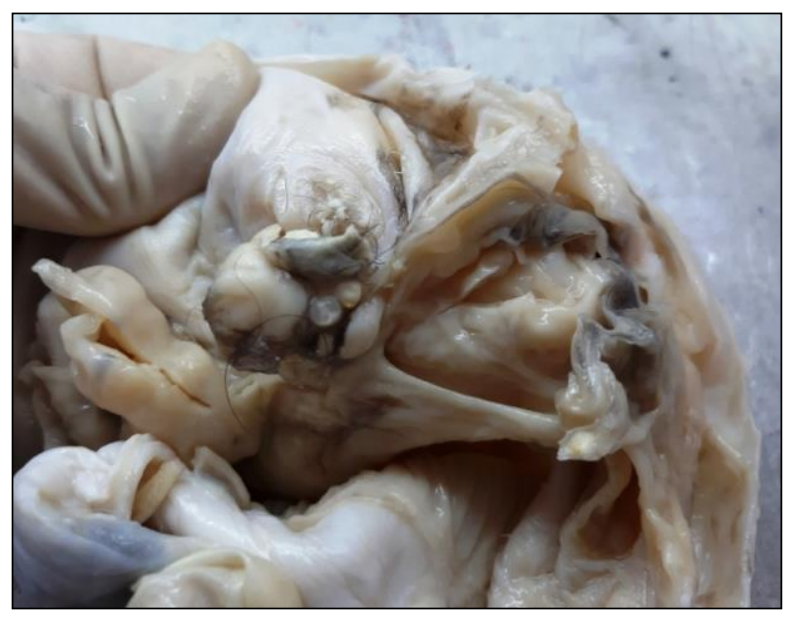

Figure 3: Specimen of cystic ovarian teratoma and benign cystademoma. 
Authors had a case of cystic ovarian teratoma associated with benign cystademoma of ovary (Figure 3).

The total 82 cases of ovarian lesions were evaluated. The cases of ovarian teratomas were 18 , which are given in Table 1 . In these 17 cases were benign teratomas, 1 case of immature teratoma.

Table 1: Distribution of cases on various histological types of ovarian teratoma.

\begin{tabular}{|lll|}
\hline $\begin{array}{l}\text { Ovarian teratomas on } \\
\text { histopathology }\end{array}$ & Cases & Percentage \\
\hline Mature & 17 & $94.4 \%$ \\
\hline Immature & 01 & $05.6 \%$ \\
\hline Monodermal & 00 & $00 \%$ \\
\hline Total & 18 & $100 \%$ \\
\hline
\end{tabular}

Table 2: Location wise case distribution of ovarian teratoma.

\begin{tabular}{|lll|}
\hline Laterality & Cases & Percentage \\
\hline Right & 08 & $44.45 \%$ \\
\hline Left & 10 & $55.55 \%$ \\
\hline Bilateral & 00 & $00 \%$ \\
\hline Total & 18 & $100 \%$ \\
\hline
\end{tabular}

The cases of teratoma were more on left sided ovary $(55.55 \%)$, right sided ovary was involved in $44.5 \%$ cases. The distribution on location are given in Table 2.

Table 3: Age-wise case distribution of ovarian teratoma.

\begin{tabular}{|cll|}
\hline Age distribution & Cases & Percentage \\
\hline $0-10$ & 0 & $0 \%$ \\
\hline $11-20$ & 1 & $05.55 \%$ \\
\hline $21-30$ & 4 & $22.22 \%$ \\
\hline $31-40$ & 6 & $33.33 \%$ \\
\hline $41-50$ & 4 & $22.22 \%$ \\
\hline $51-60$ & 3 & $16.68 \%$ \\
\hline Total & 18 & 100 \\
\hline
\end{tabular}

The age range in this study was from 20 to 60 year. The common age observed was in group 31-40 years having 6 cases. The 3 cases were in the age group of 51to 60 year which constitute $16.68 \%$. The distribution is given as below in Table 3 .

The surgically excised specimens of ovarian mass lesions were examined for detail for gross and microscopic feactures, the details are as given below. The gross pathologic appearance of mature cystic teratomas is characteristic. The tumors are unilocular in most of cases and are filled with sebaceous material.

The histological studies were done for confirmatory diagnosis of ovarian teratoma and its type. The photomicrograms showed various histopathlogical types of ovarian mature cystic teratoma with variable amount of endodermal, ectodermal and mesodermal tissue. $(\mathrm{H}$ and E stain, 40x) (Figure 4).

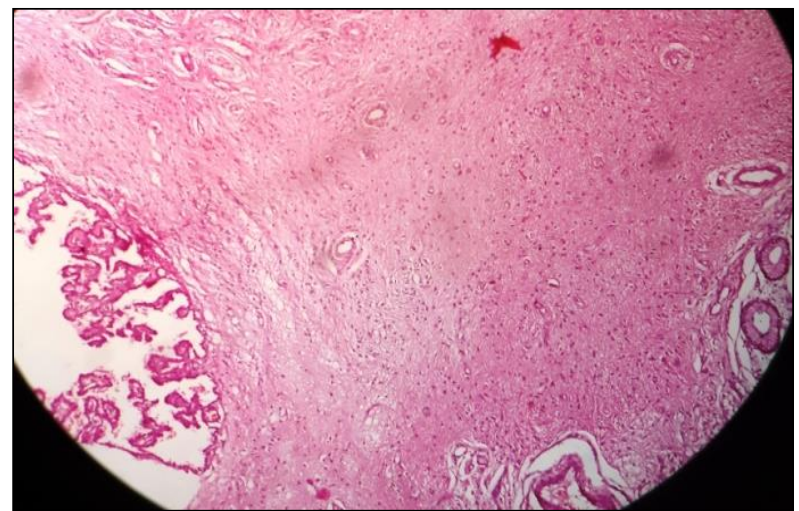

Figure 4: The photomicrogram of ovarian mature cystic teratoma with variable amount of endodermal, ectodermal and mesodermal tissue. (H and E stain, 40x).

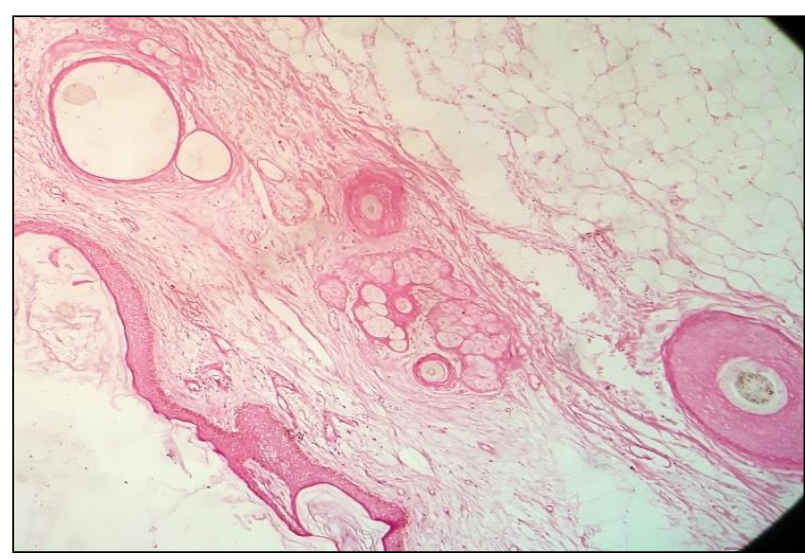

Figure 5: The photomicrograph of ovarian mature cystic teratoma with predomint ectodermal and adipose tissue. (H and $\mathrm{E}$ stain, 40x).

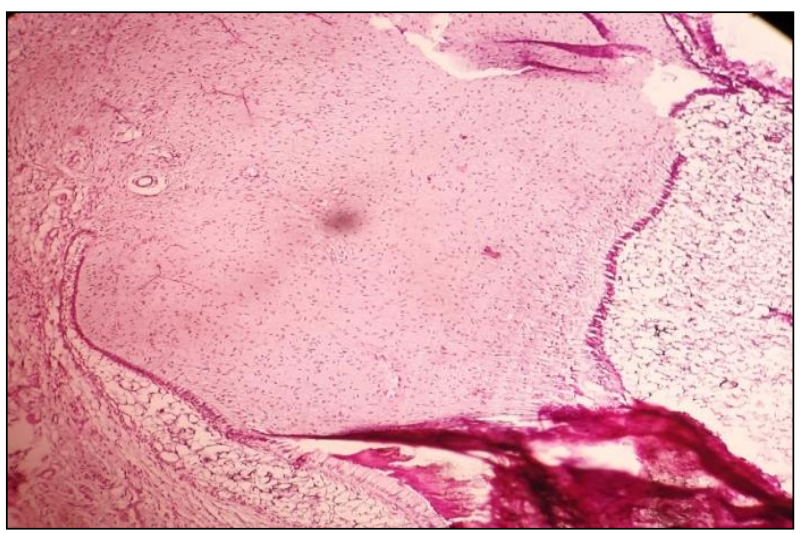

Figure 6: The photomicrograph showing ovarian mature cystic teratoma with neural and endodermal tissue. (H and E stain, 40x). 


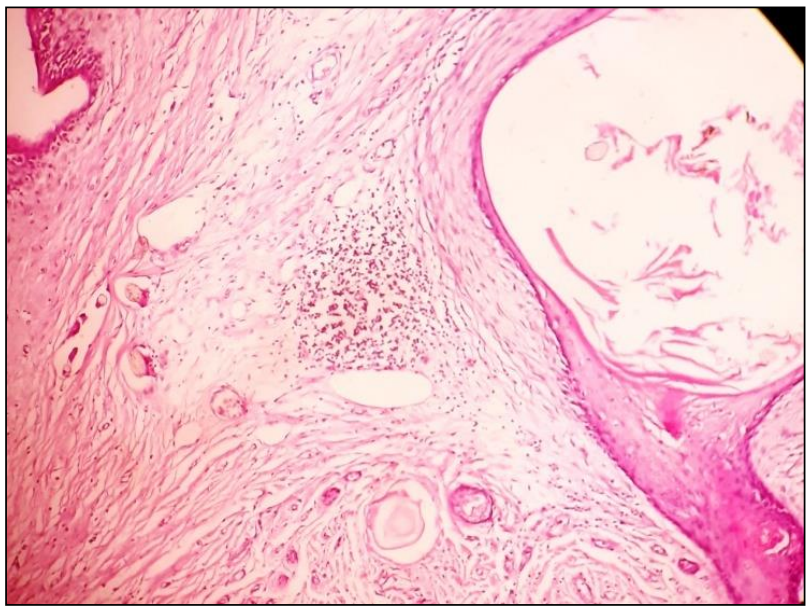

Figure 7: The photomicrogram of ovarian mature cystic teratoma with secondary inflammation and gaint cell reaction. ( $\mathrm{H}$ and $\mathrm{E}$ stain, $40 \mathrm{x}$ ).

The squamous epithelium lining the wall of the cyst was observed in most of cases. The photomicrograph showing ovarian mature cystic teratoma with predomint ectodermal and adipose tissue as shown in Figure 5.

We observed a case of immature (malignant) teratoma showing ovarian mature cystic teratoma with neural and endodermal tissue. ( $\mathrm{H}$ and $\mathrm{E}$ stain, 40x) as shown in Figure 6. The associated microscopic findings noted were secondary inflammation and gaint cell reaction as shown in Figure 7.

All the patients responded well to the treatment in our study.

\section{DISCUSSION}

Thurlbeck and Scully has given first description of teratoma. ${ }^{5}$ Teratomas are most commonly found in the gonads -ovary and testis. Extragonadal teratomas are rare and arises from midline structures such as brain, thyroid, mediastinum, pericardium, retroperitonium, etc. It is also rarely noted in other solid organs like liver, breast, salivary glands and hollow organs like oesophagus, stomach, uterine cervix and urinary bladder. ${ }^{4,6}$ A disorder of genomic imprinting is considered as an important mechanism in pathogenesis of ovarian teratomas.

Teratoma comprise of mature and immature tissue of pleuripotential (germ cell) origin. Mature teratomas consist nearly one third of all benign ovarian neoplasm. ${ }^{7}$ Various adult type of differentiated components such as skin, glandular epithelium, cartilage, bone, teeth etc are the main component of it. In this study the ectoderm is the common histological component. The common type of teratoma noted (Table 1) in this study was mature cystic teratoma which constitutes $94.4 \%$ among 18 cases of teratoma and $21.9 \%$ among total 82 cases of ovarian neoplasms. Mature cystic teratoma constitute $15-20 \%$ of all ovarian tumors. ${ }^{89}$ The peak incidence in most of the studies is reported in early adolescence. ${ }^{4}$ Our study showed age range between 20 to 60 years (Table 3 ). The most commmon clinical features noted in various studies were nonspecific lower abdominal pain, palpable abdonminal mass and distension. ${ }^{10}$ The common clinical features in our study was chronic nonspecific pelvic or abdominal pain $(85 \%)$. Asymptomatic mature cystic teratomas of the ovaries have been reported at rates of 6$65 \%$ in various series. In our study all cases were unilateral. Other studies showed unilaterality 75-90\%, and bilaterality in 10 to $15 \%$ of cases. ${ }^{11}$

In clinically suspected cases of pelvis/ovarian masses various preoperative modalities like ultrasonography, CT scan and MRI features are helpful for diagnosis of teratomas and its differentiation. ${ }^{12,13}$ The specimen histological study give confirmatory diagnosis and its type. The microscopic examination shows variable amount of endodermal, ectodermal and mesodermal tissue. It consist of adnexal tissue, fat, muscle, skin, cartilage, hair, teeth, nerves, neuronal tissue, thyroid, respiratory tissue etc. In this study ectodermal tissue skin and adnexa were predominant. Cut section of mature teratomas mostly shows cyst filled with thick sebaceous material and desquamated squamous epithelium with tufts of hair.

Authors observed a case of immature (malignant) teratoma. Incidence of immature teratoma is rare and account for approximately 0.2 to $1 \%$ of all ovarian tumors. It represents $3 \%$ of all teratomas. ${ }^{14}$ Immature teratoma is composed of mixture of embryonal and adult tissue derived from all three germ layers. As per WHO it is defined as a teratoma containing variable amount of immature embyonal type (usually neural epithelium) tissue. ${ }^{15}$ The proportion of immature tissue elements defines the grade of immaturity from grade 0 to grade 3 . For early age occurrence of teratoma foci of yolk sac tumor must be looked carefully to determine the diagnosis, assisted with tumor marker study. Another phenomenon like glomatosis peritonei is to look for.

For an immature teratoma it must be extensively sampled at grossing to detect immature component. We have one case in patient of age 23 year. It showed presence of immature embryonic tissue, mostely glial tissue and rosette like tumor cellular arrangement. Areas of necrosis, myxoid change and hemorrhage were also noted. Immature teratoma is rare occurrence and usually seen unilateral.

The amount of immature element determines the prognosis of these cases. ${ }^{16}$ Malignant teratoma also includes teratoma with malignant transfer matrix also designated as somatic type tumors. We have one case showing cystic mature teratoma transforming with squamous cell carcinoma moderately differentiated. The most common malignant change in mature cystic teratoma is squamous cell carcinoma has been noted in various studies. 
Other types of monodermal teratomas neural type have been described. Monodermal teratomas with neuroectodermal differentiation can form benign, or primitive neuroectodermal tumors and they clinically are more aggressive in nature. ${ }^{17}$

The complications associated with teratomas are usually cyst rupture leading to leakage of sebaceous fluid in the abdominal cavity causing peritonitis. In our study one case was presented with peritonitis. Other complications like torsion, malignant transformation have been reported. ${ }^{18,19}$ Squamous cell carcinoma arising from the squamous lining of the cyst is the most common type of malignant change. The overall prognosis is determines by tumor growth, size, histological type, evidence of capsular/vascular invasion, rupture of cyst etc. The management options for mature cystic teratomas include cystectomy or unilateral salpingo-oophorectomy, which gives excellent results. All the patients responded well to the treatment in our study. In case of immature teratomas the histologic grade and fertility desires of the patient are key considerations in determining treatment options.

\section{CONCLUSION}

In this study, showed mature cystic teratoma is the most common type of ovarian teratomas. The immature and monodermal types are rare. The histopathological examination play important role in final diagnosis and patient management.

Funding: No funding sources

Conflict of interest: None declared

Ethical approval: The study was approved by the Institutional Ethics Committee

\section{REFERENCES}

1. Wesselschmidt RL. The teratoma assay: an in vivo assessment of pluripotency. Methods Mol Biol. 2011;767:231-41.

2. Linder D, McCaw BK, Hecht F. Parthenogenic origin of benign ovarian teratomas. N Engl J Med. 1975;292:63-6.

3. Caruso PA, Marsh MR, Minkowitz S, Karten G. An intense clinicopathologic study of 305 teratomas of the ovary. Cancer. 1971;27:343-8.

4. Comerci JT, Licciadi F, Bergh PA. Mature cystic teratoma: a clinicopathologic evaluation of 517 cases and review of literature. Obstet Gynecol. 1994;84:22-8.

5. Thurlbeck WM, Scully RE. Solid teratoma of the ovary. A clinicopathologic analysis of 9 cases. Cancer. 1960;13:804-11.
6. Ulbright TM. Gonadal teratoma review and speculation. Adv Anat Pathol. 2004;11:10-23.

7. Kumar V, Abbas AK, Fausto N. The female genital tract: Pthologic Basis of diseases, 8th Ed. Sanuders; 2010: 1047-1048.

8. Chiang AJ. Squamous cell carcinoma arising from mature cystic teratoma of the ovary. Int $\mathrm{J}$ Gynecol Cancer. 2011;21:466-74.

9. Schneider DT, Terenziani M, Cecchetto G, Olson TA. Gonadal and extragonadal germ cell tumors, sex cord stromal and rare gonadal tumors. In: Schneider D, Brecht I, Olson T, Ferrari A, editors. Rare tumors in children and adolescents. Pediatric Oncol Berlin Springer; 2011: 327-402.

10. Kim MJ, Kim NY. Clinical characteristics of ovarian teratoma: age focused retrospective analysis of 580 cases. Am J Obstet Gynecol. 2011;205:e1-e32.

11. Al-Fozan H, Glassman J, Caspi B, Appelman Z, Tulandi T. Lateral distribution of ovarian dermoid cyst. J Am Assoc Gynecol Laparosc. 2003;10:48990.

12. Patel MD, Feldstein VA, Lipson SD, Chen DC, Filly RA. Cystic teratomas of the ovary: diagnostic value of sonography. AJR Am J Roentgenol. 1998;171:1061-5.

13. Guerriero S, Mallarini G, Ajossa S. Transvaginal ultrasound and computed tomography combined with clinical parameters and CA-125 determinations in the differential diagnosis of persistent ovarian cysts in premenopausal women. Ultrasound Obstetr Gynecol. 1997;9:339-43.

14. Quirk JT, Natarajan N. Ovarian cancer incidence in the United States, 1992-1999. Gynecol Oncol. 2005;97:519-23.

15. Nogales F, Talerman A, Kubik-Huch RA, Tavassoli FA, Devouassoux-Shisheboran M. In: World Health Organisation. Classification of Tumours. Pathology and Genetics Tumours of the Breast and Female Genital Organs. Tavassoli FA, Devilee P, eds. Lyon: IARC Press; Germ Cell Tumours; 2003:163-175.

16. Heifetz SA, Cushing B, Giller R, Shuster JJ, Stolar $\mathrm{CJ}$, Vinocur $\mathrm{CD}$, et al. Immature teratomas in children: pathologic considerations: a report from the combined Pediatric Oncology Group/Children's Cancer Group. Am J Surg Pathol. 1998;22:1115-24.

17. Young RH. New and unusual aspects of ovarian germ cell tumors. Am J Surg Pathol. 1993;17:121024.

18. Jagtap SV, Dhawan SD, Jagtap SS, Kshirsagar NS. Mucinous cystadenocarcinoma ovary presented as giant pelvic-abdominal mass. Int $\mathrm{J}$ Med Sci Pub Health. 2016;3:10:1305-8.

19. Park SB, Kim JK, Kim K, Cho KS. Imaging findings of complications and unusual manifestations of ovarian teratomas. Radiographics. 2008;28(4):969.

Cite this article as: Jagtap SV, Kshirsagar NS, Jagtap SS, Boral S, Nasre N. Ovarian teratomas: clinicopathological study at tertiary care center. Int J Reprod Contracept Obstet Gynecol 2019;8:3318-22. 